\title{
THE EFFECT OF CH4 PLASMA TREATMENT ON LOW DIELECTRIC HSQ FILMS
}

\author{
${ }^{\#}$ GUIQIN YIN, QIANGHUA YUAN \\ Key Laboratory of Atomic and Molecular Physics \& Functional Materials of Gansu Province, \\ College of Physics and Electronic Engineering, Northwest Normal University, Lanzhou 730070, China \\ "E-mail: yinguiq@126.com
}

Submitted March 25, 2018; accepted May 22, 2018

\begin{abstract}
Keywords: Ceramics, Thin films, Sol-gel
The commercial hydrogen silsesquioxane (HSQ) is made up from low-density and low dielectric constant (low-k) materials. In this paper, low-k HSQ films are obtained by spin-on deposition (SOD) and then followed by treatment with $\mathrm{CH}_{4}$ plasma using electron cyclotron resonance (ECR). Fourier-transform infrared spectroscopy (FTIR) is used to identify the network structure and cage-like structure of the $\mathrm{Si}-\mathrm{O}-\mathrm{Si}$ bonds and other bonds. Capacitance-voltage $(\mathrm{C}-\mathrm{V})$ measurements are used to determine the dielectric constants. A slow positron beam is conducted in order to investigate the pore connectivity within these films. The results suggest that the dielectric constant of the HSQ films, which were treated with $\mathrm{CH}_{4}$ plasma, increased a little after annealing. $\mathrm{CH}_{4}$ plasma treatment can restrain the increase in the dielectric constant of the HSQ films.
\end{abstract}

\section{INTRODUCTION}

Dimensions of devices in ultra-large scale integrated circuits (ULSI) continue to shrink according to the international technology roadmap for semiconductors (ITRS), which will delay the signal propagation speed and increase power consumption. This RC delay can be solved by using high conductivity metals for the interconnects, and by using low-k materials as the dielectric [1-2]. At present, the lower dielectric constant of a film can be obtained by producing pores or reducing the polarity of the chemical bonds. Many studies focused on the characteristics of low dielectric constant materials [3-12]. Different kinds of low dielectric constant materials, such as methylsilsesquioxane (MSQ), HSQ, $\mathrm{SiCOH}$, a porous silica, silica-carbon and fluorinatedcarbon, have been investigated in recent years. HSQ has a highly porous and three-dimensional network structure, so HSQ is one of the promising candidates for $32 \mathrm{~nm}$ ULSI technology. The lower dielectric constant of the HSQ can be achieved by maximising the density of $\mathrm{Si}-\mathrm{H}$ bonds and minimising the $\mathrm{Si}-\mathrm{OH}$ bonds. On the other hand, the HSQ dielectric film was prepared by spin-on deposition that is compatible to different processes employed in ULSI [13]. It is well known that annealing is necessary in ULSI circuits in order to keep the stability and decrease the surface roughness of the devices. However, the dielectric constant commonly increases after annealing because of surface structure changes. Some different plasma treatments were found to be effective in restraining the increase in the dielectric constant after annealing. Plasma treatment can reduce the roughness of the surface and change the structure of the film. The densities of the films can be changed also, which will lead to a change in the $\mathrm{k}$-values [14]. $\mathrm{H}_{2} / \mathrm{He}$ reactive plasma clean treatment (RPC) successfully prevented $\mathrm{Cu}$ from diffusing into low-k polymer after annealing at $200^{\circ} \mathrm{C}$ for $1000 \mathrm{~h}$. This method is proven to be effective for characterising and improving pore-sealing and barrier performance for $\mathrm{Cu}$ /porous ultra-low-k interconnects [15]. Plasma treatments are identified in order to enhance adhesion without degrading the dielectric constant [16]. $\mathrm{CHF}_{3}$ plasma treatment on the $\mathrm{SiCOH}$ film lead to the reduction of the flat-band voltage $V_{\mathrm{FB}}$ shift and leakage current of the $\mathrm{Cu} / \mathrm{SiCOH} / \mathrm{Si}$ film [17]. On the other hand, the porous low-k film is damaged as it induced plasma etching radicals [18]. Air-plasma exposure can increase the defect concentrations by breaking the siliconhydrogen bonds. Nitrogen-plasma exposure, as well as free-radical exposure, has only a small influence on breaking the bond. Ultraviolet curing can improve the chemical-damage resistance of the dielectric [19].

In the paper, we chose the $\mathrm{CH}_{4}$ molecule as the plasma due to its tetrahedral structure and its $\mathrm{C}-\mathrm{H}$ bonds that can help form Si-H bonds in the HSQ films. The characteristics of the HSQ films which were treated by $\mathrm{CH}_{4}$ plasma and then followed by annealing at different temperatures was investigated. The results suggested that the dielectric constant of the HSQ film treated with $\mathrm{CH}_{4}$ plasma does not substantially increase after annealing. 


\section{EXPERIMENTAL}

The P-Si (100) wafers cleaned by standard RCA were spin-coated with HSQ at $2000 \mathrm{rpm}$ for $20 \mathrm{~s}$, and baked sequentially on a hot plate at $400^{\circ} \mathrm{C}$ for $1 \mathrm{~min}$. The $\mathrm{CH}_{4}$ plasma treatments were carried out in an ECRCVD chamber. The $\mathrm{CH}_{4}$ gas flow rate was 5 SCCM and the substrate temperature was kept at $100^{\circ} \mathrm{C}$. The MW $(2.45 \mathrm{GHz})$ power was $300 \mathrm{~W}, \mathrm{I}_{1}$ was $140 \mathrm{~A}$ and the $\mathrm{I}_{2}$ was $110 \mathrm{~A}$. The chamber pressure was maintained at 3 mTorr. These films were annealed in a furnace at $300^{\circ} \mathrm{C}$ and $400^{\circ} \mathrm{C}$ respectively for $1.5 \mathrm{~h}$ in a nitrogen ambient. The annealing time was $1 \mathrm{~min}, 2 \mathrm{~min}, 3 \mathrm{~min}, 4 \mathrm{~min}$ and 5 min, respectively.

The HSQ films' thicknesses were measured by an ET 350 profilometer. The HSQ films' chemical bonds and structures were characterised by a FTIR spectroscopy JASCO 600 Plus with $4 \mathrm{~cm}^{-1}$ resolution. The dielectric constant $(\mathrm{k})$ was calculated from the $\mathrm{C}-\mathrm{V}$ characteristics measured at $1 \mathrm{MHz}$ frequency by an HP4294A. The $\mathrm{C}-\mathrm{V}$ characteristics were undertaken on a MIS structure fabricated as Aluminium/MSQ/p-Si. Slow positron beams were conducted to investigate the pore connectivity within these films.

\section{RESULTS AND DISCUSSION}

The result of FTIR

Figure 1 shows the FTIR spectra of the HSQ films treated with $\mathrm{CH}_{4}$ plasma without annealing. The peak intensities of the $\mathrm{Si}-\mathrm{H}$ and $\mathrm{Si}-\mathrm{O}$ bonds only change a little with different $\mathrm{CH}_{4}$ plasma treatment times. The results indicate that $\mathrm{CH}_{4}$ plasma treatments have little influence on the non-annealed HSQ films.

The FTIR spectra of the HSQ films treated with $\mathrm{CH}_{4}$ plasma and annealed at $300^{\circ} \mathrm{C}$ for $1.5 \mathrm{~h}$ in a nitrogen

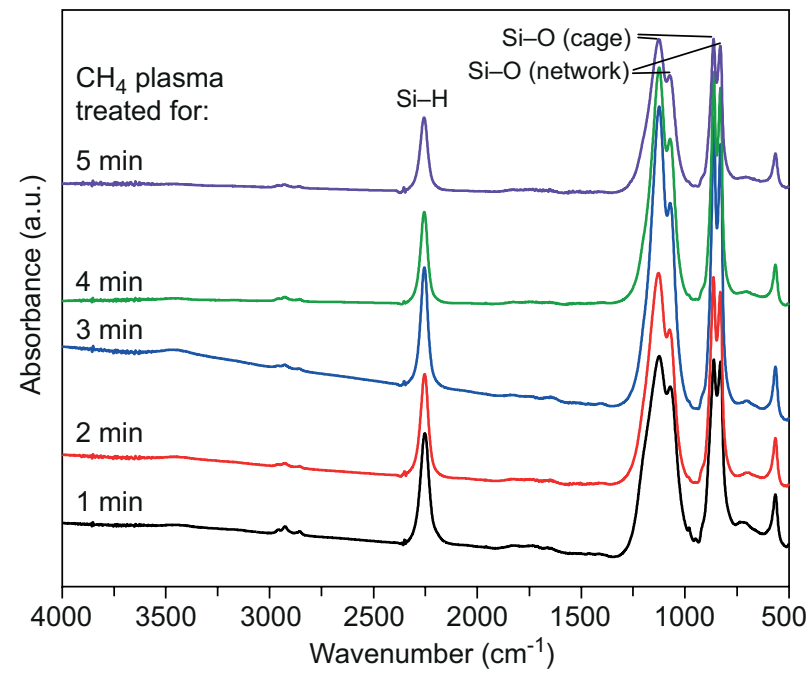

Figure 1. The FTIR spectra of the HSQ films treated with $\mathrm{CH}_{4}$ plasma without annealing. ambient is shown in Figure 2. According to the spectra, the $\mathrm{Si}-\mathrm{O}$ stretch cage-like peak $\left(1130 \mathrm{~cm}^{-1}\right)$ decreases and the $\mathrm{Si}-\mathrm{O}$ stretch network peak $\left(1070 \mathrm{~cm}^{-1}\right)$ increases when the HSQ film was treated with $\mathrm{CH}_{4}$ plasma for 1 min. However, the peak intensity of the $\mathrm{Si}-\mathrm{O}$ stretch cage-like bonds increases and the peak intensity of the $\mathrm{Si}-\mathrm{O}$ stretch network bonds decreases with an increase in the $\mathrm{CH}_{4}$ plasma treatment times. These indicate that the $\mathrm{CH}_{4}$ plasma treatments changed the structure of the HSQ films annealed at $300^{\circ} \mathrm{C}$.

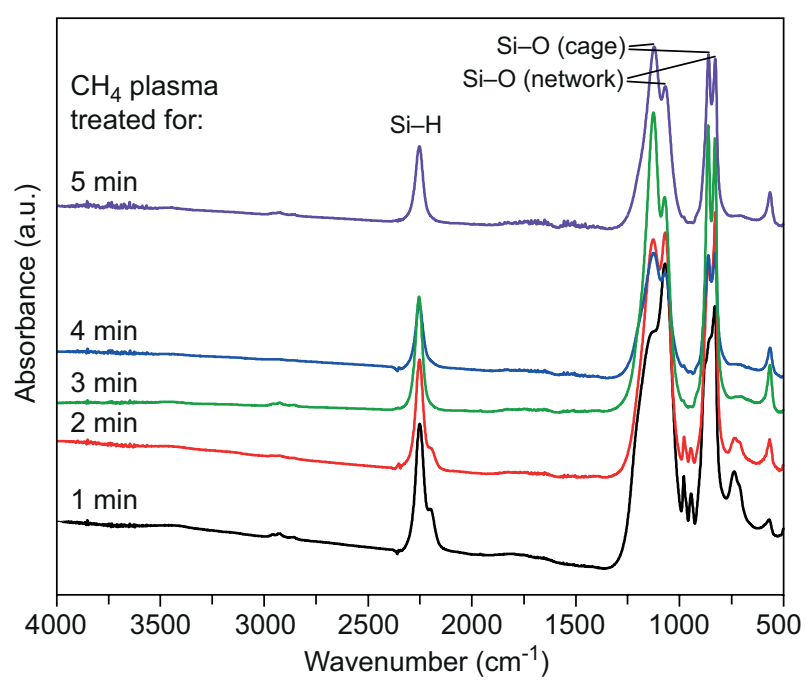

Figure 2. The FTIR spectra of the HSQ films treated with $\mathrm{CH}_{4}$ plasma and annealed at $300^{\circ} \mathrm{C}$ for $1.5 \mathrm{~h}$ in a nitrogen ambient.

The FTIR spectra of the HSQ films treated with $\mathrm{CH}_{4}$ plasma and annealed at $400^{\circ} \mathrm{C}$ for $1.5 \mathrm{~h}$ in a nitrogen ambient is shown in Figure 3. The peak intensity of the $\mathrm{Si}-\mathrm{O}$ stretch cage-like peak $\left(1130 \mathrm{~cm}^{-1}\right)$ decreases and the $\mathrm{Si}-\mathrm{O}$ stretch network peak $\left(1070 \mathrm{~cm}^{-1}\right)$ increases

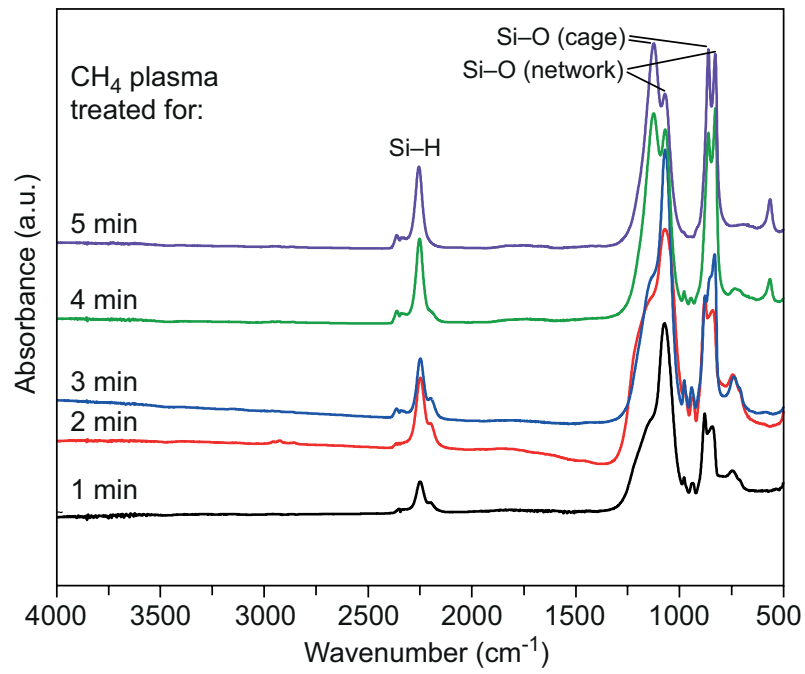

Figure 3. The FTIR spectra of the HSQ films treated with $\mathrm{CH}_{4}$ plasma and annealed at $400^{\circ} \mathrm{C}$ for $1.5 \mathrm{~h}$ in a nitrogen ambient. 
compared with that annealed at $300^{\circ} \mathrm{C}$. The peak intensity of the $\mathrm{Si}-\mathrm{O}$ bonds changes a little with an increase in the $\mathrm{CH}_{4}$ plasma treatment time, which is similar to that in Figure 2. It can be expressed as follows:

$$
\mathrm{H}-\mathrm{Si}-\mathrm{O}+\mathrm{CH}_{4}->\mathrm{Si}-\mathrm{O}-\mathrm{Si}+\mathrm{H}_{2} \mathrm{O}
$$

The $\mathrm{Si}-\mathrm{O}$ cage-like structure can decrease the density of the films, so it is a benefit to low-k materials. This indicates that $\mathrm{CH}_{4}$ plasma treatments are a benefit to keep the cage-like structure for the annealed HSQ films.

The result of relative area ratio $(\%)$ of the $\mathrm{Si}-\mathrm{H}$ bonds

The relative area ratio (\%) of the $\mathrm{Si}-\mathrm{H}$ bonds is shown in Figure 4. The relative area of the $\mathrm{Si}-\mathrm{H}$ bonds firstly increases and then decreases with an increase in the $\mathrm{CH}_{4}$ plasma treatment time. The relative area of the $\mathrm{Si}-\mathrm{H}$ bonds increases with an increase in the annealing temperature. With $2 \mathrm{~min} \mathrm{CH}_{4}$ plasma treatments, the relative area of the $\mathrm{Si}-\mathrm{H}$ bonds increased from $23.06 \%$ (at $300^{\circ} \mathrm{C}$ ) to $39.2 \%$ (at $400^{\circ} \mathrm{C}$ ). The $\mathrm{Si}-\mathrm{H}$ bonds are hydrophobic, so the HSQ films will be more hydrophobic after the $\mathrm{CH}_{4}$ plasma treatment. The hydrophobic surface will reduce the moisture uptake.

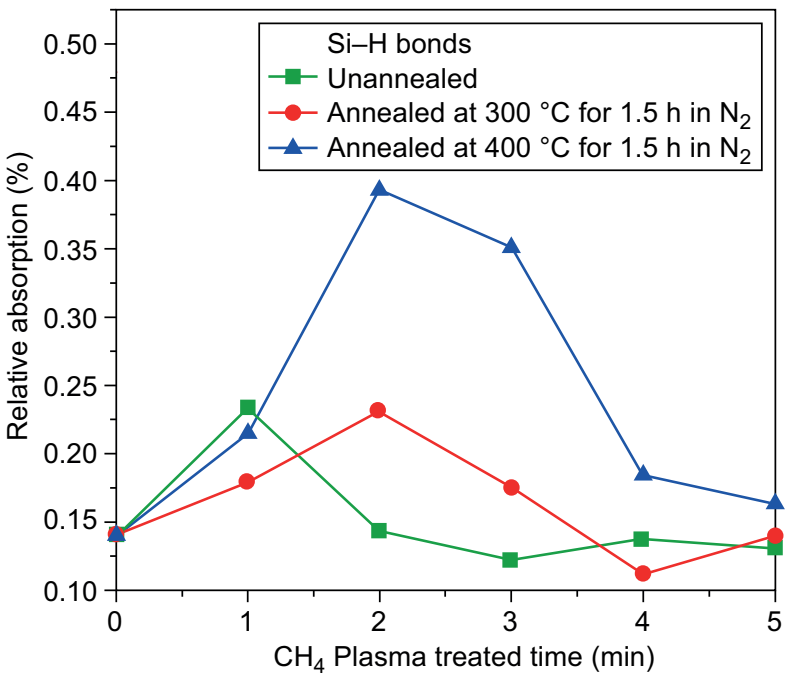

Figure 4. The relative area ratio (\%) of the $\mathrm{Si}-\mathrm{H}$ bonds (peak area/total area of spectrum between 736 and $2393 \mathrm{~cm}^{-1}$ ) for the results for Figure 1, 2 and 3.

\section{The result of dielectric constants}

The dielectric constants of the HSQ films treated with different $\mathrm{CH}_{4}$ plasma treatment times are shown in Figure 5. The dielectric constant increases with an increase in the $\mathrm{CH}_{4}$ plasma treatment time for the non-annealed sample. It is 3.02 for the sample that was treated with $\mathrm{CH}_{4}$ plasma for $3 \mathrm{~min}$. The dielectric constants of the annealed samples are higher than the non-annealed samples. It is 3.12 at $300^{\circ} \mathrm{C}$ and 3.15 at $400^{\circ} \mathrm{C}$, respectively, with $\mathrm{CH}_{4}$ plasma treatment for 1 min. The dielectric constants of the annealed HSQ films and non-annealed HSQ films all decrease with an increase in the $\mathrm{CH}_{4}$ plasma treatment time. The increase in the dielectric constant is due to the conversion of the $\mathrm{Si}-\mathrm{O}$ cage-like structure into the $\mathrm{Si}-\mathrm{O}$ network in the $\mathrm{CH}_{4}$ plasma treatment and the annealed samples. The conversion decreases with an increase in the $\mathrm{CH}_{4}$ plasma treatment time. The $\mathrm{Si}-\mathrm{O}$ cage-like structure is a benefit to keep the low density of the HSQ films, so the dielectric constant of the annealed samples increased slightly with an increase in the $\mathrm{CH}_{4}$ plasma treatment time.

The dielectric constants of the annealed HSQ films will increase due to the conversion of the structure. We found that the dielectric constants of the HSQ films, which were treated with $\mathrm{CH}_{4}$ plasma, increased slightly after annealing, so the $\mathrm{CH}_{4}$ plasma treatment can keep the low dielectric constant. The properties of the $\mathrm{SiOCH}$ films can be significantly enhanced by $\mathrm{CH}_{4}$ plasma treatment also [20].

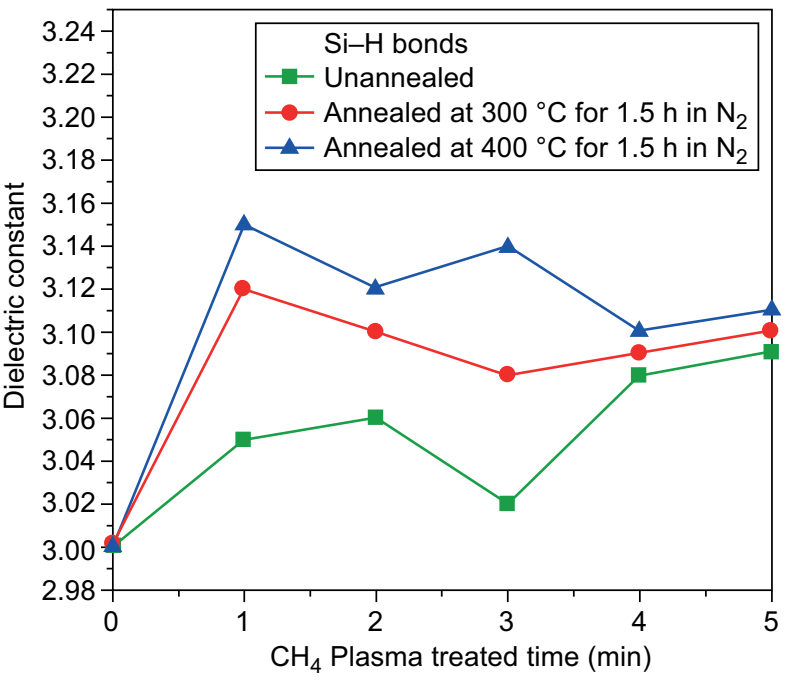

Figure 5. The dielectric constant of the annealed and nonannealed HSQ films with various $\mathrm{CH}_{4}$ plasma treatments time.

\section{The results of slow positron beam measurements}

The results of slow positron beam measurements are shown in Figure 6. The $\mathrm{S}$ values are shown as a function of the positron implantation energy. The $\mathrm{S}$ data of the sample treated with $\mathrm{CH}_{4}$ plasma for $3 \mathrm{~min}$ and $5 \mathrm{~min}$, and then annealed at $300^{\circ} \mathrm{C}$ for $1.5 \mathrm{~h}$ in a nitrogen ambient, are lower than the others. This means that the implantation depths of these samples are smaller than the others [21]. This suggests that the porous density is smaller than the others as the porous density is proportionate to the implantation depth. As shown in Figure 6, it is similar to the samples treated with the $\mathrm{CH}_{4}$ plasma for $5 \mathrm{~min}$ with and without annealing 
at $400^{\circ} \mathrm{C}$ for $1.5 \mathrm{~h}$ in a nitrogen ambient. These results show that the porosities of the HSQ films treated with $\mathrm{CH}_{4}$ plasma changed a little after annealing at $400^{\circ} \mathrm{C}$. The low-density materials have low dielectric constants. The dielectric constant of the HSQ films treated with $\mathrm{CH}_{4}$ plasma increased slightly after being annealed at $400^{\circ} \mathrm{C}$. The $\mathrm{S}$ data of the sample treated with $\mathrm{CH}_{4}$ plasma for $5 \mathrm{~min}$ and annealed at $300^{\circ} \mathrm{C}$ for $1.5 \mathrm{~h}$ in a nitrogen ambient is lower than that annealed at $400^{\circ} \mathrm{C}$. The reason may be that the higher annealing temperature destroys the $\mathrm{Si}-\mathrm{O}$ bonds and produces porosities. These results suggest that a proper annealing temperature can keep proper porosities.

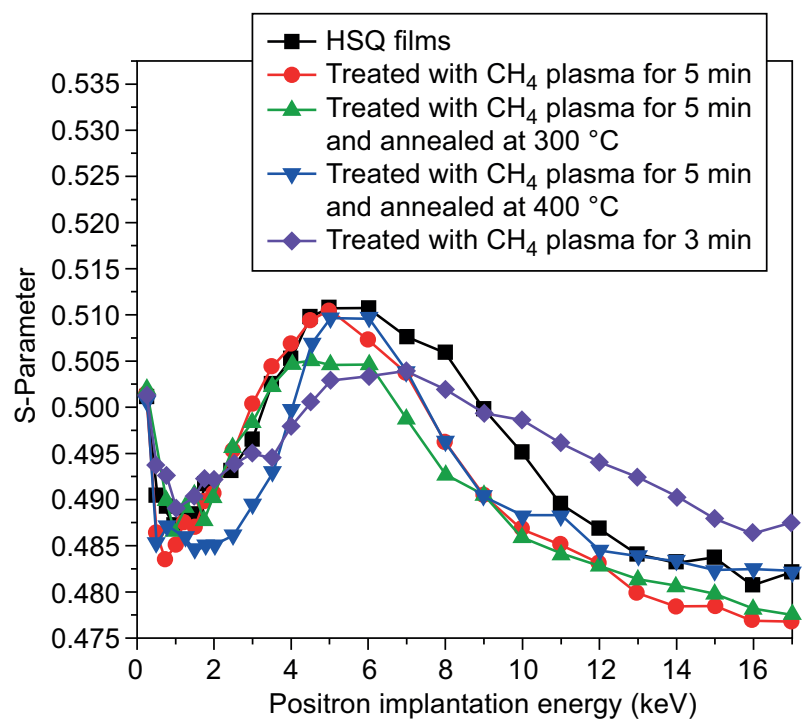

Figure 6. The s-parameter vs. the positron implantation energy (slow positron beam measurements).

\section{CONCLUSIONS}

The effect of $\mathrm{CH}_{4}$ plasma treatment for stabilising low dielectric HSQ films has been investigated. As it is known, annealing is an important step in obtaining ULSI. The structure and the electrical properties, such as the leakage current density and the dielectric constant of the annealed HSQ films are more stable than that of the non-annealed one. In this paper, we concluded that: (1) $\mathrm{CH}_{4}$ plasma treatment can prevent the structure of the annealed HSQ films from becoming destroyed from the FTIR results. (2) The results of the slow positron beams also suggest that the porosities of the HSQ films treated with $\mathrm{CH}_{4}$ plasma only changed a little after being annealed. (3) $\mathrm{CH}_{4}$ plasma treatment can keep the characteristics (low leakage current density and low dielectric constant) of the HSQ films after annealing. Therefore, $\mathrm{CH}_{4}$ plasma treatment is an effective method to keep the low dielectric constant of the annealed HSQ films.

\author{
Acknowledgements
}

The authors gratefully acknowledge the support provided by the Project of Natural Science Foundation of China (11165012), the Project of Natural Science Foundation of GanSu province (145RJZA159).

\section{REFERENCES}

1. Zhao X. Y., Liu H. J. (2010): Review of polymer materials with low dielectric constant. Polymer International, 59(5), 597-606. doi: 10.1002/pi.2809

2. Chen Y. H., Jeng U. S., Leu J. (2011): Effect of curing on the porogen size in the low-k MSQ/SBS hybrid films. Journal of The Electrochemical Society, 158(3), G52-G57. doi: 10.1149/1.3529246

3. Yin G., Yuan Q., Ning Z. (2013): Synthesis and structure characterization of low dielectric constant MSQ films by using octamethyl cyclotetrasiloxane (D4) as a porosity promotion agent. Vacuum, 96, 59-62. doi: 10.1016/j.vacuum. 2013.03.007

4. Volksen W., Miller R. D., Dubois G. (2009): Low dielectric constant materials. Chemical reviews, 110(1), 56-110. doi: $10.1021 / \operatorname{cr} 9002819$

5. Liu P. T., Chang T. C., Hsu K. C., Tseng T. Y., Chen L. M., Wang C. J., Sze S. M. (2002): Characterization of porous silicate for ultra-low $\mathrm{k}$ dielectric application. Thin solid films, 414(1), 1-6. doi: 10.1016/S0040-6090(02)00423-6

6. Wang X., Yuan Q., Zhou Y., Yin G., Dong C. (2014): Deposition of Polymer Thin Film Using an Atmospheric Pressure Micro-Plasma Driven by Dual-Frequency Excitation. Plasma Science and Technology, 16(1), 68. doi: 10.1088/1009-0630/16/1/15

7. Chen Y.H., Tu H.E., Leu J.(2012): Effect of surfactants on the porogen size in the low-k methylsilsesquioxane/polystyrene hybrid films. Microporous and Mesoporous Materials, 162, 181-188. doi: 10.1016/j.micromeso.2012.05.042

8. Maex K., Baklanov M. R., Shamiryan D., Lacopi F., Brongersma S. H., Yanovitskaya Z. S. (2003): Low dielectric constant materials for microelectronics. Journal of Applied Physics, 93(11), 8793-8841. doi: 10.1063/1.1567460

9. Yin G., Yuan Q., Ning Z. (2012): Repairing oxygen plasma-damaged on low dielectric constant MSQ (methylsilsesquioxane) films with anneal. Journal of electroceramics, 28(1), 70-73. doi: 10.1007/s10832-011-9679-y

10. Yin, G., Ning, Z., Yuan, Q., Ye, C., \& Xin, Y. (2007). Structure characterization of HSQ films for low dielectrics uses D4 as sacrificial porous materials. Journal of the American Ceramic Society, 90(6), 1943-1945. doi: 10.1111/ j.1551-2916.2007.01713.x

11. Yin G. Q., Ning Z. Y., Yuan Q. H. (2007): Structure characterization of HSQ films for low dielectrics using D5 as sacrificial porous materials. Chinese Physics Letters, 24(12), 3532. doi: 10.1088/0256-307X/24/12/066

12. Yuan Q. H., Yin G. Q., Ning Z. Y. (2013): Effect of oxygen plasma on low dielectric constant HSQ (Hydrogensilsesquioxane) films. Plasma Science and Technology, 15(1), 86. doi: 10.1088/1009-0630/15/1/14

13. Seraji S., Wu Y., Forbess M., Limmer S. J., Chou T., Cao G. Z. (2000): Sol-Gel-Derived Mesoporous Silica Films with Low Dielectric Constants. Advanced Materials, 12(22), 
1695-1698. doi: 10.1002/1521-4095(200011)12:22<1695:: AID-ADMA1695>3.0.CO;2-V

14. Yang P., Lu D., Kumar R., Moser H. O. (2005). Influence of plasma treatment on low-k dielectric films in semiconductor manufacturing. Nuclear Instruments and Methods in Physics Research Section B: Beam Interactions with Materials and Atoms, 238(1-4), 310-313. doi: 10.1016/j. nimb.2005.06.068

15. Chen X. T., Gui D., Mo Z. Q., Du A. Y., Chi D. Z., Wang W. D. et al. (2006): Effect of plasma process on low-k material and barrier layer performance. Thin solid films, 504(1-2), 248-251. doi: 10.1016/j.tsf.2005.09.160

16. Humbert A., Mage L., Goldberg C., Junker K., Proenca L., Lhuillier J. B. (2005): Effect of plasma treatments on ultra low-k material properties. Microelectronic engineering, 82(3-4), 399-404. doi: 10.1016/j.mee.2005.07.022

17. Xing Z. Y., Ye C., Yuan J., Xu Y. J., Ning Z. Y. (2009): Effect of CHF3 Plasma Treatment on the Characteristics of SiCOH Low-k Film. Plasma Science and Technology, 11(6), 674. doi: 10.1088/1009-0630/11/6/08
18. Iba Y., Ozaki S., Sasaki M., Kobayashi Y., Kirimura T., Nakata Y. (2010): Mechanism of porous low-k film damage induced by plasma etching radicals. Microelectronic Engineering, 87(3), 451-456. doi: 10.1016/j.mee.2009.07.027

19. Ren H., Jiang G., Antonelli G. A., Nishi Y., Shohet J. L. (2011): The nature of the defects generated from plasma exposure in pristine and ultraviolet-cured low-k organosilicate glass. Applied Physics Letters, 98(25), 252902. doi: 10.1063/1.3601922

20. Yang C. S., Yu Y. H., Lee H. J., Lee K. M., Choi C. K. (2005): The effect of the $\mathrm{CH} 4$ plasma treatment on deposited $\mathrm{SiOC}$ $(-\mathrm{H})$ films with low dielectric constant prepared by using TMS/O2 PECVD. Thin Solid Films, 475(1-2), 150-154. doi: 10.1016/j.tsf.2004.07.019

21. Brusa R. S., Spagolla M., Karwasz G. P., Zecca A., Ottaviani G. et al. (2004): Porosity in low dielectric constant $\mathrm{SiOCH}$ films depth profiled by positron annihilation spectroscopy. Journal of applied physics, 95(5), 2348-2354. doi: 10.1063 /1.1644925 